Brit. F. industr. Med., 1966, 23, 322

Miscellanea

\title{
The Appointed Factory Doctor Service: Just a Face-lift or a New Breed?
}

\author{
R. F. L. LOGAN \\ From the Medical Care Research Unit, University of Manchester
}

The practice of medicine is more resistant to change than even industry or education when it is presented with advances in science or technology. Until the discovery of the sulphonamides in the late 1930s, when clinical science did not exist even as a name, there was no need for change in the institutions delivering the static medical knowledge in general practice, in hospital, or in public health. Although advances in clinical science have been taking place over the last 30 years, three decades is too short a time for the second oldest profession to adjust its practice because it deals with human beings and not with machines. Even now, in facing the main killers of arterial disease and cancer, it has to rely on its art. Thus, today, general practice is still a cottage industry served from a corner shop rather than from a supermarket. Hospital practice carries on at the tempo of the buildings which it inherited from the last century, and public health, after its successes in the primary prevention of infection, has mixed feelings about secondary prevention by pre-symptomatic detection of latent morbidity. The tertiary prevention of handicap and invalidity by rehabilitation and adjustment of the family to chronic disease, is not being faced by any sector of medicine. Yet the final test of any modern system of delivering medical skills is not the acute episode requiring care in bed but the ambulant and recurring degenerative diseases in middle and later life, including mental handicap, as they progress with age into 'geriatrics'. This changed pattern of disease, in which the contrast between curative and preventive medicine is meaningless, may remain with every developed country for the rest of the century. It is against this setting of sickness today that this important report (The Appointed Factory Doctor Service, 1966) -an outline sketch if not a hopeful blue print - of a viable national scheme of comprehensive industrial medicine for the future has to be judged.

Received for publication May 27, 1966.
The first certifying surgeons authorized by the Factories Act in 1844 were responsible only for certifying that a child to be employed in a textile mill was of the ordinary strength and appearance of a child of 9 years or over. (Until the 1950s in China, without birth certificates, the child was weighed.) After the introduction of statutory registration of births in 1837 the first chief inspector of factories in 1878 saw no reason why medical men should go into factories, but the first doctor employed as H.M. Inspector advocated the medical supervision of workers of all ages so that industrial efficiency might be increased. In that dark century, with its toll from the infectious diseases, notification and isolation were the epidemiological methods of control. When a physician had little more than his senses to aid him in diagnosis, notification of established industrial disease and periodic medical examinations of workers could at least record the tip of the iceberg above the surface and exclude the unfit from work. At the same time, it was frequently the one opportunity for the labouring classes to see a doctor.

This was the best they could do in those days, and the system fitted the times. With such a direct lineage the ingrained habits of thought carried over to 1948. Then the duties of the appointed factory doctor (A.F.D.) were increased to include more physical examinations-yet this was an era of increasingly fit generations of youth and of the second industrial revolution when working conditions were becoming increasingly light and safe. Thanks to the good feeding of wartime food rationing, and to antibiotics being freely available from family doctors, school leavers were so fit physically that the traditional physical medical examination was a waste of time. With only the crude aid of his senses in screening the masses of robustly healthy youth it was little wonder that the clinical acumen of the A.F.D. became blunt with an equal risk of either over or under diagnosing. (Lee (1958) found that the school health service had not diagnosed 
$50 \%$ of the asthmatics and the cardiacs, $45 \%$ of the epileptics, and $15 \%$ of the enuretics who were later rejected at National Service examination.) Yet the 1948 regulations introduced a medical examination within 14 days of a youth's first job in a factory and on changing from one factory to another (as adolescents do), to be repeated at least annually until the age of 18 ; and this was at the time of the introduction of the National Health Service when a personal doctor was made freely available to everyone. Despite these obvious criticisms at that time (Logan, 1958), the mis-application of medical skills to the wrong population at the wrong time continued, with diminishing returns, and in 1964, with an increasing shortage of medical manpower, some 2,000 doctors statutorily 'examined' half a million young workers.

This report now accepts these criticisms honestly and recommends two main changes. The first is 'the elimination of unnecessary examinations, particularly of young persons', and the second is 'the redeployment of medical resources to bring about a more compact, integrated and expert medical service with wider duties over the whole field of occupational health'.

There was always a gap in medical administration and supervision when the adolescent left the shelter of school for the hurly-burly of work. Although the Factories Act, 1948 provides that every Local Education Authority should arrange for the A.F.D. to be furnished, on his application, with the school medical records of an individual adolescent, such requests are almost unknown. In theory, the schoolchild was examined during his last term at school by the school doctor and again by the A.F.D. within a week of taking up his first job. This report proposes to eliminate this duplication and throws a line across the gap by handing over to the School Health Service the responsibility, in the first instance, for the medical examination of young persons taking up employment in factories. A health permit for work would be given to the schoolchild (and copies posted to the Youth Employment Officer and the family doctor). The adolescent would present it to his first employer to be recorded in the factory register, and would only be seen by the new-style A.F.D., the ' $A$ ' doctor, if the school doctor considered any of the six categories of work might be unsuitable for the adolescent-work requiring normal hearing or fine vision or involving dust, fumes, dermatitis risk, heavy lifting, or working at heights or near moving vehicles.

The report makes two big assumptions about the School Health Service: first, that about $5 \%$ of school leavers may have physical health handicaps for work. Such an estimate would have applied at the turn of the century and through the Hungry Thirties in the era of rickets, rheumatic heart disease, and cripples from infected bone and poliomyelitis, and up to the Second World War. In those grim years, too, effort in the factory derived as much from human sweat and muscle as from coal and steam.

In the changed picture of robust, healthy youth today, handicaps are rare, more likely to be mental than physical, and these mainly congenital and less acquired. Out of every 1,000 schoolchildren 20 are mentally retarded and six are at a special school, 15 have difficulties with hearing and 15 with speech, three are epileptic and two blind, and the occasional one crippled with cerebral palsy, spinal dystrophy, muscular dystrophy, or asthma, or diabetes. Of the Io emotionally maladjusted secondary schoolchildren, 30 will be enuretic and to will be regularly attending a child guidance clinic. Possibly another outlet for difficulties in emotional adjustment is reflected in delinquency, and by the age of 16 one in 20 boys has been found guilty of an offence (little changed since Ferguson's classical follow-up of school leavers in Glasgow back in 1952). At medical examination for National Service the main causes for rejection, after visual defects, asthma, and congenital heart disease, are psychosomatic, particularly enuresis (does this affect his work ?) and dyspepsia.

The national shortage of doctors was felt first by the School Health Service in the 1950s (and it has not yet reached industrial medicine). Faced first with a threatened breakdown in the system of routine physical medical examinations and only later questioning their efficacy, the School Health Service has been deploying its limited resources of doctors and nurses by using technicians for the better screening of vision and hearing, and sending questionnaires out to parents to seek the medical history and common problems of adolescent emotions, enuresis and epilepsy, which were not revealed anyway at the traditional examinations. With increasing awareness that truancy and absence from school was social sickness in a family and not a juvenile crime, the punitive School Attendance Officer is now replaced by the Welfare Officer attempting to carry on medical social case work within the home (Peterson, 1965).

Of the 2,500 doctors in the school service only 146 are full-time and some 620 are in general practice or are married women. To base the physical health permit for work on such a revamped and changing screening system at school is the second big assumption which calls for some study. Certainly for such school doctors to take on even such a primitive sort 
of vocational guidance, they will need 'retreading' and some understanding of the different satisfactions sought from work and thereby the different meaning of the job for girls as clerks or machine minders and for boys as apprentices to a trade, as semi-skilled machinists or drivers' mates or van boys in dead-end jobs or the dullard unable to exercise his excellent physique as navvying becomes mechanized. Indeed, how is the school leaver prepared for industrial 'progress' with fragmentation of work, automation, shorter working hours, and the confusion of roles of workers and management in the factory, if not nationally. As the sweat has gone out of a job so have the other human satisfactions of personal skill or pace or seeing an obvious product. The worker is less able to identify with a small group of mates in a small department and so the social satisfactions at work may also be diminished. What does a high labour turnover or the increasing 'sickness' absence mean to physicians in terms of morale or the social health of the workshop? To the modern teenager in the eternal adolescent search for identity-'to find himself'this old-fashioned and 'square' report about his own problems is 'just not with it'.

After seven pages devoted to adolescents, paragraph 4I states: 'Young people have in the past been singled out for medical examination and to a lesser extent should continue to be so in the future, because they have some characteristic which makes them more vulnerable than the generality of the factory population. The Sub-committee considered whether any group of adults could be regarded as falling in the same category'. Then the other vulnerable groups of chronic sick, the disabled, and ageing are dismissed in less than a page by assuming that the chronic sick are being supervised by the general practitioner, the disabled by the D.R.O., and that the Employment Exchange is placing older workers. However, it is left open to these agencies to seek out the ' $A$ ' doctor for advice. Yet it is these very groups who suffer the largest sickness rates and absence from work. Moreover, these rates have been steadily rising over the past Io years-and with full employment-so that today one in 12 men in their late fifties and onwards is incapacitated for work for over three months-and few ever return to work.

To wait until the late fifties in these days of piece work and speed is probably too late to prevent this premature withdrawal from the labour force. It is traumatic enough to suffer a little death by compulsory retirement at 65 without having to bring this forward into the fifties. There is, therefore, evidence that the outstandingly high risk group at work today are middle-aged men, and the late forties are not too early to think of counselling with the objective of transfer or training for a job that will carry these workers into their sixties. The nation still accepts the anachronism of the bygone era of surplus labour, of compulsory retirement at age 65 when many a fit worker is passed across from the Ministry of Labour to the Ministry of Health. Denied the chance of working for a full wage, he is also deprived of a working role.

At least there is no sex discrimination in this report-female labour is just not mentioned. Yet the proportion of women at work is higher today than in wartime when work was compulsory. Moreover, with a marriage rate at its highest $(95 \%)$ and the fertility rate continuing high, more mothers are at work than ever before. With the wear and tear of running both a home and a job, $7 \%$ of women have haemoglobins below $70 \%$.

There are other blind spots in the report. There is no mention of the Regional Medical Officer (R.M.O.) and his regiment of part-time G.P.s 'doing medical boards' on workers certified by their own family doctor as too sick for work. Perhaps this was a deliberate kindness between Ministries towards another medical anachronism which also will sometime have to take a long, hard look at itself. It is interesting that these areas of obsolete medical routines which waste limited medical resources when the profession acts as monitors for the government still persist.

Assessment of needs and determination of priorities can no longer be dealt with piecemeal service by service. The compound nature of the needs themselves and their interaction with several administrative agencies demand a more unified approach (Jeffreys, 1965). Medicine must free itself from the historical shackles of statutory enforcement with its penal powers. Both the A.F.D. and the R.M.O. should discard their unnecessary police helmets and seek to work hatless as medical advisers. Indeed, much of their role should be pastoral out in the community seeking to relate the bits and pieces of the health and social services more effectively to help the worker and his industry. Such a new breed of industrial physician will at least need two mature nurses and a secretary, particularly as he must continue part of his time in the main stream of clinical practice. Besides the initial training of such a corps d'élite the industrial physician will need some built-in system for maintaining and improving his professional competence and this could mean changing the responsibilities of university departments of occupational health. These are only a few preliminary implications if this report is going to be 
a real break with the past and to lead to a national occupational health service coping with the needs of the twentieth century. If this Sub-committee have managed to open the door to the future then they have done a good job of work.

\section{REFERENCES}

The Appointed Factory Doctor Service. Report by a SubCommittee of the Industrial Health Advisory Committee (I966). H.M.S.O., London.
Jefferys, Margot (1965). An Anatomy of Social Welfare Services. Michael Joseph, London.

Lee, J. A. H. (1958). Brit. med. F., 1, 573

Logan, R. F. L. (1958). Chapter 6 in The Matrix of Medicine, Ed. Malleson, N., pp. 80-99. Pitman Medical Publishing Co., London.

Peterson, P. (1965). Chapter 29 in The Theory and Practice of Public Health. Ed. Hobson, W., 2nd ed. Oxford University Press, London.

\section{The July (I966) Issue}

The July (1966) issue contains the following papers:-

Evolution of Concepts in Industrial Medicine. T. A. LloYd Davies

The Safety of Physically Disabled Drivers. LARS YSANDER

Relevance of Respiratory Symptoms and Signs to Ventilatory Capacity Changes after Exposure to Grain Dust and Phosphate Rock Dust. Bryan Gandevia and Blair Ritchie

Prevalence of Byssinosis and Dust Levels in Flax Preparers in Northern Ireland. P. C. Elwood,

I. R. Mcaulay, R. H. Mclarin, J. Pemberton, G. C. R. Carey, and J. D. Merrett

Design Factors and Use of Ear Protection. C. G. RICE and R. R. A. Coles

Prognostic Aspects of Benzene Poisoning. S. Hernberg, M. Savilahti, K. Ahliman, and S. Asp

Peripheral Neuropathy in Rats Produced by Acrylamide. Pamela M. Fullerton and J. M. Barnes

Toxicity of Triphenyltin. H. B. STONER

Radiochemical Determination of Metallic Vapour in Air. L. MAGos

Biliary Excretion of Lead in the Rat. N. Castellino, P. LAmanNa, and B. Grieco

Miscellanea

Twins with Coal-workers' Pneumoconiosis. J. E. M. Hutchinson

\section{Book Reviews}

A number of copies are still available and may be obtained from the Publishing Manager, British Medical Association, Tavistock Square, W.C.I, price $18 s .6 d$. 